\title{
Projeto de robô hidráulico para o ensino dos conceitos de hidrostática em aulas exploratórias
}

Hydraulic robot project for the teaching of hydrostatic concepts in exploratory classes

\author{
N. F. Souza ${ }^{1 \mathrm{a}} ;$ E. R. Granhen ${ }^{1 \mathrm{~b}}$ \\ ${ }^{1}$ Faculdade de Física da Universidade Federal do sul e sudeste do Pará, 68505-080,Marabá-PA, Brasil \\ a neyson.ferreira@yahoo.com.br \\ ${ }^{b}$ granhen@unifesspa.edu.br
}

(Recebido em 27 de agosto de 2016; aceito em 02 de novembro de 2016)

\begin{abstract}
Apresentamos o resultado do estudo exploratório sobre a construção de robô hidráulico afim de se promover uma aprendizagem significativa, sobre conceitos de hidrostática, ao alunos do primeiro ano do ensino médio. As atividades experimentais, sejam em laboratório ou em sala de aula, são ferramentas importantes que ajudam na compreensão dos fenômenos físicos. O projeto de construção de robô hidráulico foi aplicado em três turmas do primeiro ano do ensino médio no Centro de Ensino Luzia Aires Maranhão, na cidade de Carolina - Maranhão. A pesquisa foi realizada com 95 alunos em quatro etapas: na primeira, foi aplicado um questionário sobre conceitos de hidrostática com objetivo de avaliar os conhecimentos prévios dos alunos; na segunda foi ministrado o conteúdo, seguindo o seguinte planejamento; aula expositiva dialogada com aplicação de experimentos simples em sala de aula; na terceira a construção do robô hidráulico e para finalizar, na quarta etapa do trabalho revimos o questionário para se verificar o ganho na aprendizagem dos alunos. Com esse trabalho foi possível constatar que a atividade experimental em sala de aula é uma estratégia com grande potencial para desenvolver a aprendizagem significativa no ensino de Física contanto que seja feito um planejamento contemplando a participação dos discentes. Em nossa pesquisa utilizamos a teoria de aprendizagem significativa de David Ausubel.

Palavras-chave: robô hidráulico, aprendizagem significativa, atividade experimental
\end{abstract}

We present the results of the exploratory study on the construction of hydraulic robot in order to promote meaningful learning on hydrostatic concepts, the first-year secondary school students. The experimental activities, whether in the laboratory or in the classroom, are important tools that help in the understanding of physical phenomena. The hydraulic robot construction project was implemented in three of the first year of secondary school classes in the Education Center Luzia Aires Maranhão, in the city of Carolina Maranhão. The survey was conducted with 95 students in four stages: first, a questionnaire on hydrostatic concepts to evaluate the students' prior knowledge was applied; the second was given the content on the following schedule; expository dialogic class with application of simple experiments in the classroom; the third building of the hydraulic robot and finally, the fourth stage of the work we reviewed the questionnaire to verify the gain in student learning. With this work it was found that the experimental activity in the classroom is a strategy with great potential to develop meaningful learning in teaching physics as long as it made a planning including the participation of students. In our research we use meaningful learning theory of David Ausubel.

Keywords: hydraulic robot, meaningful learning, experimental activity

\section{INTRODUÇÃO}

Pesquisas na área de Ensino da Física mostram que é importante haver uma ligação entre o conteúdo de física ensinado em sala de aula e a pratica experimental, sendo essa, uma estratégia que pode levar o aluno a compreender e aprender os conceitos de Física.

Existem basicamente cinco motivos para envolver os alunos durante as atividades experimentais [1]:

1. Motivar, estimulando o interesse e o prazer de investigar;

2. Treinar destrezas laboratoriais;

3. Enfatizar a aprendizagem do conhecimento científico;

4. Percepcionar o método científico e adquirir perícia na sua utilização;

5. Desenvolver certas "atitudes científicas" como abertura de espírito e objetividade. 
Nesta pesquisa enfatizamos o uso de atividades experimentais como estratégia de ensino, pois ainda hoje, a maioria das escolas utiliza como recursos de ensino somente o livro didático e o quadro de giz, mesmo dispondo de um leque de sugestões que servem como estratégia de ensino tipo: atividades experimentais em sala de aula, simulações, vídeo aulas, aulas em slides e jogos online etc.

Em um trabalho de Neves-Saraiva [2], os autores deixam claro que as investigações a cerca do trabalho experimental em sala de aula apresentam suas potencialidades tanto do ponto de vista dos alunos quanto dos professores, no entanto ainda é um referencial ainda pouco aproveitado.

Fizemos uso das dessas atividades experimentais em consonância com o conteúdo dos livros didáticos dos alunos, juntamente com o uso de algumas demonstrações experimentais simples em sala de aula. Entre os objetivos que devemos constatar é se o conteúdo do livro didático, quando auxiliado pelo experimento, torna-se suficiente para envolver o aluno fazendo com que o mesmo possa interagir com o professor de forma espontânea.

Em [3] os autores apontam que o ensino de física praticado na maioria das escolas pública continua sendo feito de forma tradicional, o professor utilizando como única ferramenta o livro didático, ou seja, o ensino voltado para a transmissão de informações através de aulas expositivas, usando metodologias voltadas para a resolução de exercícios. Aqui exploramos o conteúdo de hidrostática usando como metodologia a aplicação de atividades simples e experimentos manuseáveis para abordar os subsunçores necessários à introdução do assunto. $\mathrm{O}$ tema de hidrostática é pouco trabalhado nos livros didáticos cujo conteúdo se dá nos últimos capítulos do $1^{\circ}$ ano do ensino médio, por isso muitas vezes o professor, por diversos fatores, que podem lhe ser alheios, nem chega ministrá-los, dai vem à importância de enfatizar esse conteúdo propondo a realização do experimento como estratégia de ensino.

Durante a construção do robô hidráulico, focamos nos conceitos relacionados ao princípio de Pascal, vasos comunicantes e transmissão de força através de líquidos. Esses conteúdos estão diretamente envolvidos em alguma aplicação tecnologia que possa fazer parte do cotidiano do aluno, nos canteiros da construção civil, máquinas de tratores, usam o princípio de Pascal, este pode ser um dos exemplos. Buscamos nesse sentido, desenvolver experimentos que despertem a curiosidade dos mesmos, fazendo com que eles possam desenvolver uma aprendizagem significativa através de atividades experimentais, que os envolva e façam ligar esses conteúdos a conhecimentos prévios. Vale salientar que o experimento proposto, que é a construção de um robô hidráulico, foi realizado em sala de aula com a supervisão do professor. Neste momento o professor é um coadjuvante da experiência, apenas mediando o conhecimento compartilhado entre os alunos e todos com ele. Para a realização da atividade experimental o professor deve fornecer todos os materiais e ferramentas necessários para a construção do experimento. O robô hidráulico pode ser montado e desmontado logo em seguida, permitindo assim ser reutilizado em outras turmas.

\section{SUBSUNÇORES DA TEORIA DE APRENDIZAGEM SIGNIFICATIVA DE DAVID AUSEBEL}

Em meados da década de 60, David Paul Ausubel criou a teoria de aprendizagem significativa. Essa teoria define o conceito de aprendizagem significativa como um processo através do qual uma nova informação se relaciona, de maneira substantiva (não literal) e não arbitrária, a um aspecto relevante da estrutura cognitiva do indivíduo [4]. Percebe-se que as novas informações devem-se relacionar com o conhecimento prévio do aluno para que a aprendizagem significativa aconteça.

Nesse processo, a nova informação interage com uma estrutura de conhecimento específica, a qual Ausubel chama de "conceito subsunçor" ou simplesmente "subsunçor", existente na estrutura cognitiva de quem aprende [4]. A aprendizagem significativa ocorre quando novas informações assumem significados e são agregadas à estrutura cognitiva de forma não arbitrária e pouco rigorosa, possibilitando a diferenciação, elaboração e estabilidade dos conhecimentos existentes [5]. Para alcançar uma aprendizagem significativa é preciso seguir um planejamento que contemple a organização do conteúdo a ser ensinado. 
O grande objetivo da educação formal é a organização da informação para os alunos, a exposição de ideias de forma clara e precisa, e a facilitação de sua aquisição de forma significativa [6]. Nesse sentido devemos usar estratégia que dê significado ao ensino e os novos conteúdos possam ser retidos por longos períodos de tempo como um conjunto de conhecimentos organizados. No entanto a aprendizagem significativa ocorre quando o aprendiz consegue atribuir significado ao que está sendo aprendido, porém estes significados têm sempre atributos pessoais [4].

O professor deve considerar que cada aluno tem sua forma individual de aprender, de acordo com David Ausubel, e o ensino deve ser oferecido de forma organizada respeitando suas peculiaridades.

Nesse sentido, "Ausubel vê o armazenamento de informações no cérebro humano como sendo organizado, formando uma hierarquia conceitual, na qual elementos mais específicos de conhecimento são ligados e assimilados a conceitos mais gerais, mais inclusivos" [4].

Acreditamos que, por meio da construção do robô hidráulico, seja possível desenvolver uma metodologia que contribua para a aprendizagem, de algum modo mais significativo, dos conceitos de hidrostática.

\section{MATERIAL E MÉTODOS}

Para a construção do robô hidráulico dispusemos de uma ideia do custo estimado para o professor poder implementar este trabalho em sala de aula. É possível que esta estimativa possa variar de região para região, no entanto continua sendo uma proposta muito interessante para ser empregada pelo professor em sua localidade. Sendo assim, disponibilizamos os seguintes materiais para a sua construção (ver Tabela 1):

Tabela 1: Lista de materiais utilizados e custo de cada item. Os valores desta tabela foram estimados no comércio da cidade de onde foi realizada pesquisa deste trabalho, Carolina-MA.

\begin{tabular}{lll}
\hline Quantidade & Material utilizado & Preço \\
\hline 20 & Peças de madeira de vários tamanhos & A madeira foi doada \\
01 & Rolamento de carro & $\mathrm{R} \$ 11,00$ \\
\hline 01 & Parafuso grande com quatro porcas e quatro ruelas & $\mathrm{R} \$ 4,20$ \\
\hline 03 & Seringas de $20 \mathrm{ml}$ & $\mathrm{R} \$ 4,50$ \\
05 & Seringas de $10 \mathrm{ml}$ & $\mathrm{R} \$ 5,00$ \\
06 & Dobradiças pequenas & $\mathrm{R} \$ 6,00$ \\
60 & Parafusos de vários tamanhos & $\mathrm{R} \$ 9,00$ \\
\hline 01 & Mangueira de aquário (5 metros) & $\mathrm{R} \$ 5,00$ \\
01 & Braçadeira de metal & $\mathrm{R} \$ 0,50$ \\
\hline 12 & Braçadeira de plástico & $\mathrm{R} \$ 3,60$ \\
02 & Liga de dinheiro & $\mathrm{R} \$ 0,20$ \\
\hline 01 & Cola araldite & $\mathrm{R} \$ 15,00$ \\
02 & Tinta amarela & $\mathrm{R} \$ 9,00$ \\
\hline 04 & Folhas de lixa & $\mathrm{R} \$ 4,00$ \\
04 & Luvas de bicicleta & $\mathrm{R} \$ 6,00$ \\
\hline Total & & $\mathbf{R} \$ \mathbf{8 3 , 0 0}$ \\
\hline
\end{tabular}


Toda a construção do robô hidráulico é realizada pelo professor como podemos ver na Figura 1 em que cada parte do robô é mostrada desmontada. Cada componente é facilmente encontrado no mercado e tem custo acessível, permitindo que a atividade possa ser replicada em outras escolas. A quantidade e os valores estimados de cada item são mostrados na Tabela 1.

Para desenvolver a pesquisa seguimos quatro etapas:

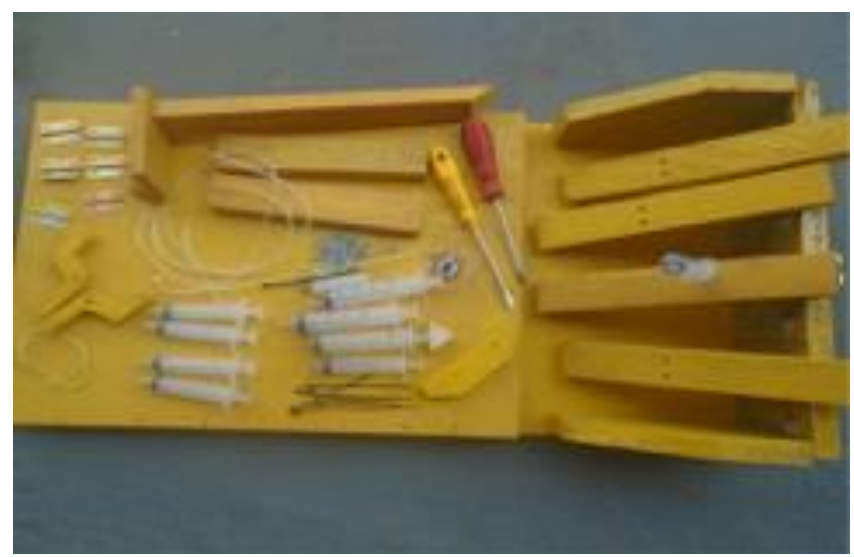

Figura 1: Material confeccionado pelo professor.

Primeira etapa - Ocorreu na aplicação de um questionário prévio com dez questões objetivas, cujo interesse é avaliar o conhecimento prévio dos alunos sobre o conteúdo a ser explorado, este questionário foi aplicado em três turmas do $1^{\circ}$ ano do ensino médio no turno matutino, um total de 95 alunos no Centro de Ensino Luzia Aires Maranhão-CELAM, uma escola da rede estadual, localizada no município de Carolina - MA. O tempo gasto para realizar essa etapa foi de 50 minutos em cada sala.

Segunda etapa - Desenvolvendo o conteúdo de hidrostática em sala de aula, utilizamos estratégias que contribuem para uma aprendizagem significativa com organizadores prévios (vídeo, experimento de baixo custo e simulações sobre a aplicação do principio de Pascal). Durante a realização do trabalho, o professor sempre procura dar ênfase às aplicações tecnológicas que possam estar ligadas ao cotidiano do aluno, como já dito anteriormente a titulo de exemplo no funcionamento de tratores e retroescavadeiras. As aulas são dialogadas e ocorrem sempre com a interação professor-aluno e aluno-aluno, possibilitando debates críticos sobre o conteúdo

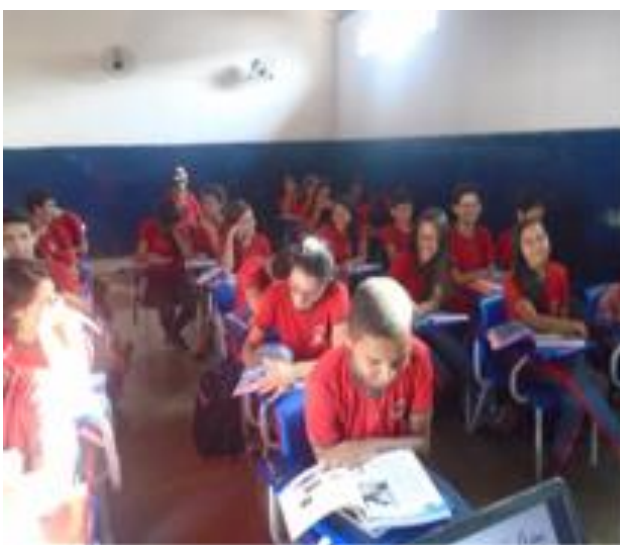

Figura 2: Turmas do Centro de Ensino Luzia Aires Maranhão-CELAM, uma escola da rede estadual, localizada no município de Carolina-MA.

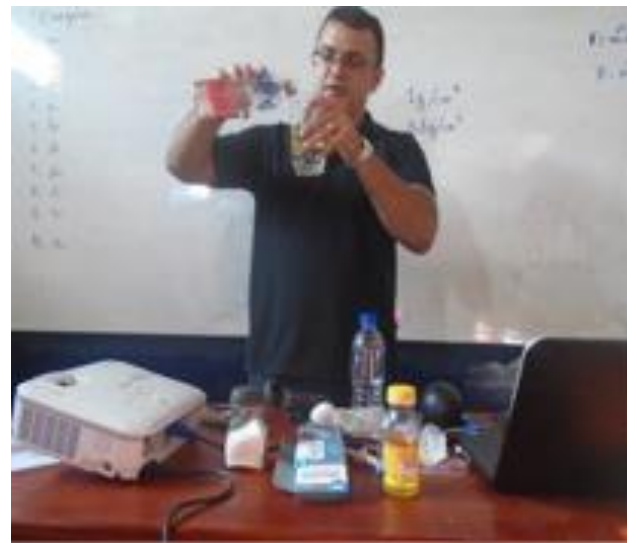

Figura 3: Desenvolvimento do conteúdo de hidrostática com demonstração de experimentos simples. Experimento de densidade e pressão hidrostática. 
estudado, este é o momento em que os alunos expõe suas ideias e confrontam suas explicações com as dos demais colegas. O tempo gasto para realizar a segunda são duas aulas de 50 minutos. Nas Figura 2 e Figura 3 mostramos a segunda etapa sendo executada. Na Figura 2 os alunos estão usando o livro didático para acompanhar a explicação do professor, enquanto que na Figura 3 o professor demonstra alguns conceitos iniciais (subsunçores que devem fundamentar o conhecimento prévio dos alunos) com o uso de experimentos simples em sala de aula.

Terceira etapa - A construção do robô hidráulico foi realizada por um grupo de alunos de cada turma. Foram selecionado 10 alunos em cada sala para montar e explicar o experimento. Durante a construção do robô hidráulico, analisamos os diferentes procedimentos executados pelos alunos para a solução de problemas propostos na montagem do robô e execução das atividades, avaliando assim a assimilação do conteúdo. Foi avaliado também o compartilhamento de dados, a tomada de decisão

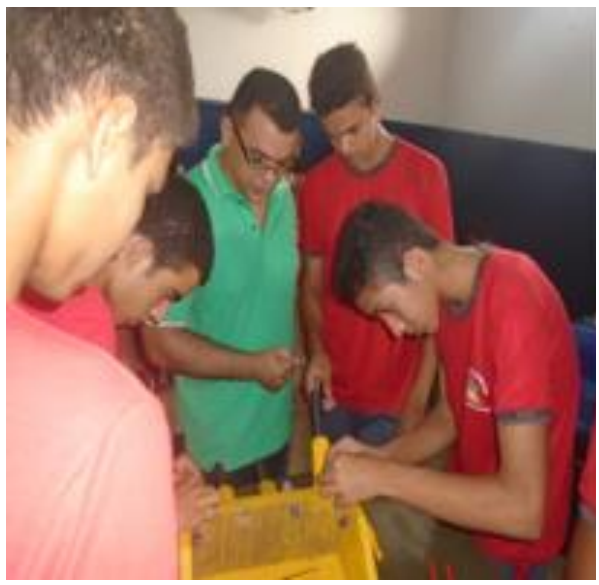

Figura 4: Construção do robô hidráulico com os alunos sob a supervisão do professor.

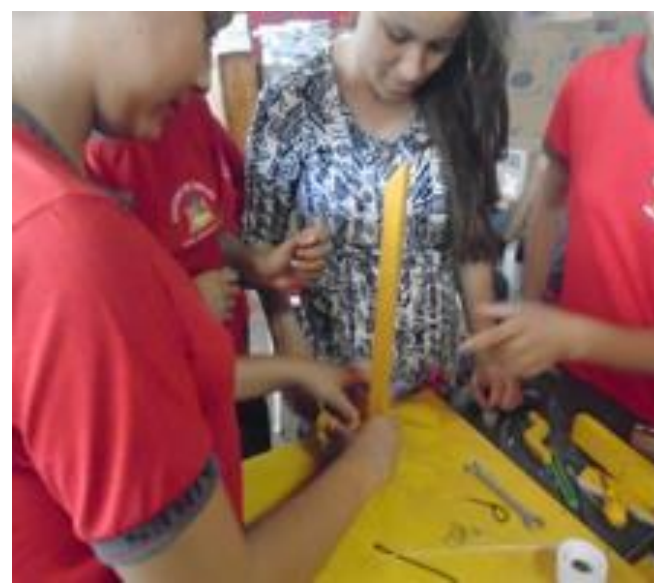

Figura 5: Colaboração entre os alunos durante a montagem do robô hidráulico.

juntamente com a criatividade na construção do objeto. Toda a atividade foi supervisionada pelo professor; os alunos dispuseram de um roteiro semi-estruturado sobre o experimento e um vídeo para ajudar na construção. Um roteiro semiestruturado permiti aos alunos proporem suas questões a cerca da atividade experimental e através da interação entre si encontrar a própria resposta à pergunta. Na Figura 4 mostramos como os alunos montaram o robô hidráulico com a supervisão do professor, enquanto que na figura 5 , durante a montagem os alunos interagem entre si, compartilhando o conhecimento entre si.

O experimento do robô hidráulico tem por objetivo mostrar como e onde o Princípio de Pascal é utilizado, explicando assim a Física do experimento - a ideia do robô é construir algo como um braço mecânico hidráulico que se movimenta por meio de um sistema de conexões de tubos e seringas. De acordo com o princípio de Pascal, a pressão exercida pelo êmbolo menor é transmitida integralmente a todos os pontos da água confinada, alcançando o êmbolo maior. Tomamos que o líquido em questão seja incompreensível, desprezando, portanto as condições de viscosidade, incompressibilidade e densidade, que o tornariam um fluido real, mas sem que essas condições possam prejudicar o experimento. Na verdade é praticamente desprezível a contribuição deste fatores. Com isso podemos dizer que a pressão é a mesma em cada ponto do fluído, o que significa que a pressão exercida nos dois êmbolos são iguais, este é o Principio de Pascal, a razão entre for e área é uma constante em qualquer ponto. No êmbolo maior ela é exercida numa área mais extensa e por isso a força nesse embolo é maior. Teoricamente, se a área do êmbolo grande for dez vezes maior que a 
área do êmbolo pequeno, a força do êmbolo grande também será dez vezes maior. $\mathrm{Na}$ realidade, o atrito entre o êmbolo e a seringa reduz muito essa relação de força. Como é difícil perceber tal redução, sugerimos passar cera de vela como forma de lubrificar os êmbolos. Explicando o funcionamento - baseado na transmissão de pressão feito na coluna de área menor, até a outra coluna de área maior. Para acionar o movimento do braço do robô o sistema consta de cinco seringas de $10 \mathrm{ml}$ e três seringas de $20 \mathrm{ml}$, ligadas por mangueiras completamente cheias de água e sem bolhas. Observação: bolhas de ar fazem o sistema perder força, já que o ar é um fluido de fácil compressão. As seringas de $10 \mathrm{ml}$ ficam cheias, enquanto as de $20 \mathrm{ml}$ ficam vazias; neste caso é possível uma multiplicação de força aplicada sobre o êmbolo das seringas de $10 \mathrm{ml}$, pois a área do êmbolo da seringa de $20 \mathrm{ml}$ é maior que o embolo de $10 \mathrm{ml}$. Assim, ao pressionar o êmbolo das seringas de $10 \mathrm{ml}$ é possível observar a seringa de $20 \mathrm{ml}$ se movimentar, e com isso observar os movimentos do braço do robô hidráulico.

Pelo princípio de Pascal, essa seringa maior tem um grande ganho de força devido a diferença de área, o que é importante, ou seja, com pequeno esforço físico conseguimos pegar, elevar e movimentar um objeto bem pesado, na prática é o que acontece em nosso cotidiano com aplicações tecnológicas como: braços mecânicos

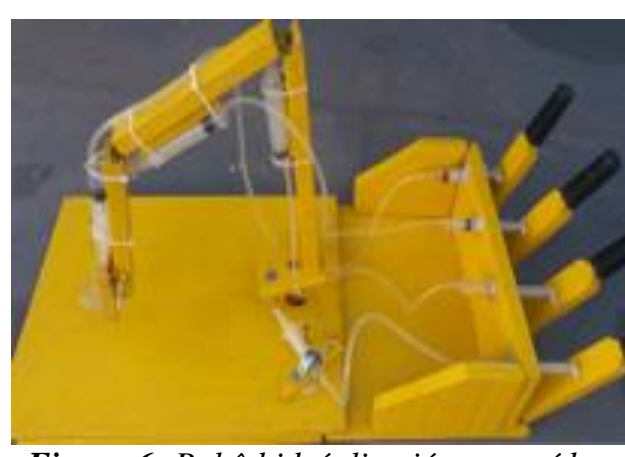

Figura 6: Robô hidráulico já construído.

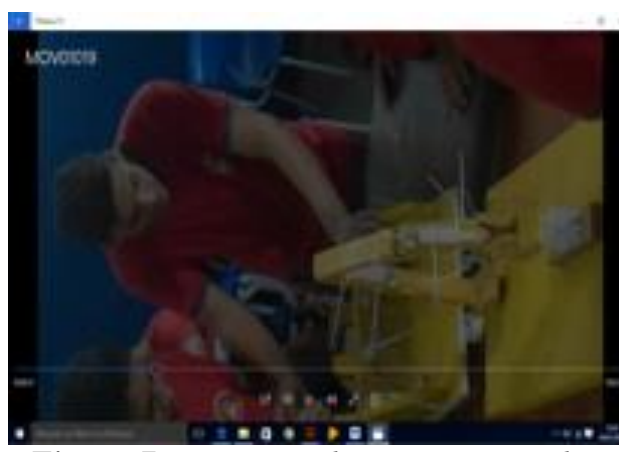

Figura 7: Execução dos movimentos do robô hidráulico com o auxílio dos alunos.

usados na indústria, braço mecânico usado nos caminhões que trocam lâmpada nos postes etc. Na Figura 6 mostramos o robô hidraúlico já construído pela turma, enquanto que na Figura 7 os alunos estão executando os movimentos no robô.

As dificuldades verificadas - o líquido utilizado no caso do robô hidráulico é a água, mesmo sabendo que não é um bom lubrificante, este fluído foi o mais adequado. Testaram-se outros líquidos: óleos diversos, álcool, detergente, todos se mostram inferiores à água, ou seja, o robô perdeu um pouco de força. Atribuímos isso ao atrito entre o plástico da seringa e os líquidos, a viscosidade do fluído também deve ser considerada. Para componentes mecânicos-metálicos, como é a situação real, num braço de escavadeira por exemplo, o fluído mais indicado não é a água, pois a mesma apresenta um certo grau de corrosão com os metais, então é indicado que se use fluídos de máquina, que apresentam densidade, viscosidade e propriedades moleculares específicas que atendem ao propósito das máquinas. O mais importante durante o teste de funcionamento do robô hidráulico é que os alunos possam perceber a possibilidade da transmissão de forças através de líquidos, o que permite inúmeras aplicações práticas elevador, freios, prensa hidráulica e uma grande quantidade de máquinas que funcionam a partir desse princípio. É importante o professor chamar atenção dos alunos para os problemas que foram constatados, e que não existem nas máquinas hidráulicas, pois os cilindros (representado aqui pelas seringas) e os êmbolos são metálicos, e preenchidos com óleo, o que reduz enormemente o atrito. 
Depois que os alunos terminaram de montar o robô é que se segue a demonstração à turma, e nesse momento também ocorre a problematização do trabalho. Como estão presentes os conceitos de Física aplicados ao experimento da construção do robô? as reflexões sobre o projeto, as dificuldades na execução das tarefas. É neste momento que o espaço é utilizado para uma reconstrução do conhecimento. De acordo com Buchweitz sobre a teoria da aprendizagem significativa de David Ausubel [6]: "Ausubel considera a estrutura do conhecimento no cérebro humano como sendo organizada, formando uma hierarquia conceitual em que os elementos mais específicos são ligados e tendem a ser assimilados pelos conceitos mais gerais ou inclusivos. Quando a nova informação adquire significado por meio da interação com subsunçores, reflete uma relação de subordinação dessa nova informação à estrutura já existente no aprendiz", e é nesse sentido que nos referimos a uma reconstrução do conhecimento.

Quarta etapa - Se deu com a aplicação dos mesmos questionários, para as mesmas turmas, agora podendo constatar o avanço no aprendizado significativo, pós-aplicação do experimento e das discussões em sala da aula. O questionário baseava-se em questões que envolviam os conceitos de densidade, pressão e vasos comunicantes.

Terminada todas as etapas podemos nos voltar a coleta de dados, organizados nas tabelas apresentadas em Tabela $\mathbf{1}$ e Tabela 2, constatadas pelas figuras de Figura 1 à Figura 7 . A seguir faremos a discussão dos resultados obtidos.

\section{RESULTADOS E DISCUSSÃO}

Analisando o desenvolvimento do estudo foi possível constatar o envolvimento de todos os alunos na realização do trabalho, havendo assim a interação entre aluno-professor e entre alunoaluno, o que permitiu uma discussão bem aprofundada sobre os conceitos de Física do ponto de vista da aplicação.

Observamos durante a realização da terceira etapa, na construção do robô hidráulico, a curiosidade dos alunos relacionando o experimento com os conteúdos ministrados em sala de aula, discutindo conceito de pressão e transmissão de força pelo fluído das seringas, e comparando a parte hidráulica com as aplicações de máquinas hidráulicas. Os alunos fizeram uso dos conhecimentos prévios com novos conteúdos, aprofundando o nível de conhecimento desses conteúdos, verificado nos resultados da terceira coluna da Tabela 2.

Vários alunos afirmaram que aprenderam melhor o conteúdo de Física da forma que foi ministrado em sala de aula, ou seja, conciliando atividades prática ao conteúdo estudado.

Tabela 2: Os dados coletados pelo questionário antes e depois da atividade experimental.

Dados da pesquisa com as três turmas do turno matutino da escola analisada

Turmas Médias da turma antes da pesquisa Média da turma após pesquisa

$\begin{array}{lll}\text { A } & 4,17 & 6,38 \\ \text { B } & 6,03 & 6,65 \\ \text { C } & 3,59 & 6,94\end{array}$

Um resultado expressivo que podemos destacar deste trabalho é o envolvimento dos alunos com as atividades, extrapolando a mera carga-horária "conteudista" que é tradicionalmente vista pelos livros didáticos ou que possa ser ministrada sem auxílio destas ferramentas de ensino. A interdisciplinaridade é discutida. Podemos ver, tanto com os resultados obtidos dos questionários usados para estabelecer um conhecimento prévio, quanto com o que podemos constatar com as perguntas realizadas pelos discentes entre si, e com o professor através da socialização das discussões, que os objetivos alcançados foram muito além de absorver os conceitos de hidrostática ou hidrodinâmica. Destacamos que o comprometimento com as atividades realizadas em sala de aula, puderam elevar o conhecimento deste conceitos nos alunos fazendo-os perceber como estes 
são úteis ao o seu cotidiano. Na Tabela 2 a seguir salientamos algumas peculiaridades das turmas analisadas. Na turma A, por exemplo, a maioria dos alunos estão em idade escolar adequada a serie que cursam, na média de 15 anos de idade e na maioria sempre estudaram em escola pública, esta turma, depois da atividade de construção do robô, das discussões promovidas pelo professor em sala de aula com a apresentação de vídeos e experimentos simples, obtiveram resultado no questionário final muito satisfatório, para uma turma de 24 alunos cerca de $70 \%$ ficaram com nota maior igual a 6,0, a turma B também apresenta alunos com uma média de 15 anos de idade, entretanto apenas alguns poucos estudaram em anos anteriores em escola pública, a grande parte veio da rede privada, isso talvez se refletiu na média apresentada no questionário que avaliou o conhecimento prévio, nesta turma cerca de $83 \%$ (26 alunos de uma turma de 31 no total) ficaram com nota maior igual a 6,0. Na turma $\mathrm{C}$ a média de idade também fica em torno de 15 anos, mas apresenta também um numero considerável de alunos com 16, 17 e 19 anos, isto porque nessa turma se concentrava a maioria dos alunos repetentes, o que pode ser o caso de refletir a mais baixa nota na avaliação do questionário de conhecimento prévio, esta turma obteve cerca de $75 \%$ dos alunos com notas maior igual a 6,0 (28 alunos de um total de 37 na turma).

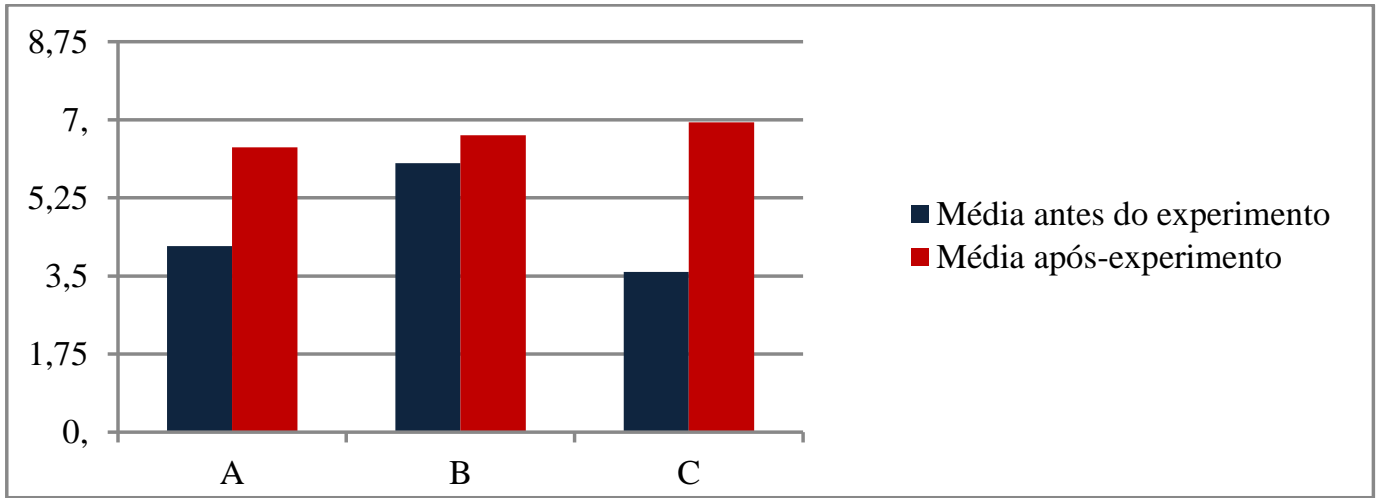

Figura 8: O Gráfico em barra mostra mais claramente o desempenho dos alunos antes e após desenvolvimento da pesquisa.

\section{CONCLUSÃO}

O trabalho apresenta a construção do robô hidráulico visando a utilização desta atividade como um recursos alternativo para explicar conceitos de hidrostática, no caso específico dessa pesquisa o princípio de Pascal. O experimento busca ser uma alternativa que estimule uma aprendizagem significativa, para tanto o professor deve considerar os conhecimentos prévios do aprendiz e trabalhar para que se possa promover o melhor desenvolvimento respeitando as potencialidades de cada indivíduo. Foram utilizados materiais acessíveis sendo possível de ser replicado esta atividade à maioria das escolas e também permitir que o próprio aluno possa montar $\mathrm{o}$ experimento com as instruções do professor, isso permite que o aluno saia da situação de mero expectador para ser um executor ou construtor do seu conhecimento.

A construção do robô hidráulico pelos alunos foi algo positivo, pois a metodologia adotada permitiu a participação de todos os alunos na construção do conhecimento, verificamos isso constatando o percentual de acertos em cada turma, o número de acertos maior ou igual a 6,0 ficou sempre acima de $70 \%$. Durante a construção dos experimentos os alunos se empenharam em realiza-lo explicando o seu funcionamento, mostrando para o que serve e onde é aplicado no cotidiano. Esta é uma atividade que pode muito bem ser aplicada em uma feira de ciências ou outra atividade escolar. O robô hidráulico requer um tempo de duas aulas (cinquenta minutos) para a sua montagem, juntamente com a explicação dos princípios de Física envolvidos.

Dessa forma julgamos que a proposta cumpriu as expectativas para alcançar os objetivos propostos. Foi necessário fazer um planejamento que abrangesse todos alunos. Finalmente esperamos ter contribuído para enriquecer as aulas de hidrostática com auxílio dessa atividade experimental, ou seja, nosso trabalho é uma alternativa onde é possível o professor tornar as aulas de física mais atraentes e dinâmicas. 


\section{AGRADECIMENTOS}

A CAPES, pelo apoio financeiro concedido através da bolsa fornecida. Ao Centro de Ensino Luzia Aires Maranhão de Carolina - MA que possibilitou a execução desta pesquisa. E aos colaboradores.

\section{REFERÊNCIAS BIBLIOGRÁFICAS}

1. Hodson, D. Trabalho Prático e Experimental na Educação em Ciências. The place of Practical Work as Science Education. Braga: Universidade do Minho; (2000).

2. Neves-saraiva M., Caballero C. E Moreira, MA. Repensando o papel do trabalho experimental, na aprendizagem da física, em sala de aula - um estudo exploratório. Rev. Investigações em Ensino de Ciências (IENCI) 2006 Dez; 11(3): 383-401.

3. Rosa CW, Rosa AB. Ensino de Física: objetivos e imposições no ensino médio. Revista Eletrônica de Enseñanza de las Ciências, 2005; 4(1).

4. Moreira MA. Teorias de aprendizagem: Um conceito subjacente, Aprendizagem Significativa em Revista/ Meaningful Learning Review. 2011 Dez; 1(3), 25-46.

5. Moreira MA. Teorias de aprendizagem. São Paulo: EPU, 1999.

6. Buchweitz, B. Aprendizagem Significativa: ideias de estudantes concluintes de curso superior. Investigações em Ensino de Ciências, v. 6, n. 2, p. 133, 2001.

7. Ausebel, D. P., Novak, J. D. and Hanesian, H. Educational Psychology: a Cognitive View ( $2^{\mathrm{a}}$ ed.). New York: Holt, Rinehart and Winston, 1978. 